SORGATO JC; ROSA YBCJ; SOARES JS; PINTO JVC; ROSA DBCJ. 2016. Luminosidade e imersão em água na aclimatização intermediária de Dendrobium phalaenopsis. Horticultura Brasileira 34: 080-085. DOI - http://dx.doi.org/10.1590/S0102-053620160000100012

\title{
Luminosidade e imersão em água na aclimatização intermediária de Dendrobium phalaenopsis
}

\author{
José C Sorgato; Yara BCJ Rosa; Jackeline S Soares; Jannaina VC Pinto; Derek BCJ Rosa \\ Universidade Federal da Grande Dourados (UFGD), Dourados-MS, Brasil; jc_sorgato@hotmail.com; yararosa@ufgd.edu.br; jacke. \\ schultz@gmail.com; jannawicca@hotmail.com; derekrosa@gmail.com
}

\section{RESUMO}

Dendrobium phalaenopsis é uma orquídea ornamental que apresenta boa porcentagem de germinação e desenvolvimento em meio assimbiótico. Entretanto, a sua aclimatização ex vitro ainda requer estudos, pois, muitas vezes ocasiona a desidratação das plantas, prejudicando seu crescimento e desenvolvimento. Objetivou-se com este trabalho, estudar o efeito conjunto do período de imersão de plantas $D$. phalaenopsis em água destilada e de duas condições de luminosidade em sua aclimatização intermediária. Plantas foram dividas em conjuntos de 40 , sendo submetidos à imersão em água por $0 ; 12 ; 24 ; 36 ; 48 ; 60 ; 72$ ou 84 horas. Após cada período de imersão as plantas foram transplantadas para recipientes contendo o substrato de plantio e posteriormente alocadas em sala de crescimento para a aclimatização intermediária por 30 dias, sendo que, um conjunto de 20 plantas de cada período (incluindo o controle) permaneceu sob luz fluorescente branca $\left(18,9 \mu \mathrm{mol} / \mathrm{m}^{2} / \mathrm{s}\right)$ e as outras 20 plantas, permaneceram sob luz fluorescente branca + luz fluorescente vermelha $\left(14,85 \mu \mathrm{mol} / \mathrm{m}^{2} / \mathrm{s}\right)$. Na sequência, foram submetidas à aclimatização definitiva em viveiro telado $\left(162,0 \mu \mathrm{mol} / \mathrm{m}^{2} / \mathrm{s}\right)$ por 10 meses. À medida que o tempo de imersão aumentou houve decréscimo nas relações de massa fresca e comprimento de pseudobulbos e no número de raízes das plantas cultivadas sob luz branca + luz vermelha, enquanto que as plantas cultivadas sob luz branca não apresentaram resposta diferenciada em relação ao tempo de imersão. A imersão em água destilada independentemente da condição de luminosidade não é recomendada para $D$. phalaenopsis.

Palavras-chave: Orchidaceae, floricultura, imersão, condições de luminosidade.

\begin{abstract}
Luminosity and water immersion in the intermediate acclimatization of Dendrobium phalaenopsis

Dendrobium phalaenopsis is an ornamental orchid that presents good germination and development in asymbiotic culture medium. However its ex vitro adaptation still requires studies, since the dehydration of seedlings may delay its growth and development. This study aimed to investigate the effects of the water immersion and two luminosity conditions in the intermediate acclimatization of D. phalaenopsis. Plants were divided into sets of 40 , and immersed in distilled water during $0,12,24,36,48,60,72$ or 84 hours. After each immersion period the plants were transferred to containers and allocated inside a growth room for intermediate acclimatization during 30 days. A set of 20 plants from each period of immersion and from the control remained under white fluorescent light $(18.9 \mu \mathrm{mol} /$ $\mathrm{m}^{2} / \mathrm{s}$ ) and the other 20 plants remained under white fluorescent light + red fluorescent light $\left(14.85 \mu \mathrm{mol} / \mathrm{m}^{2} / \mathrm{s}\right)$. Plants were acclimatized in a greenhouse $\left(162.0 \mu \mathrm{mol} / \mathrm{m}^{2} / \mathrm{s}\right)$ for 10 months. As immersion time increased, a decrease in fresh weight and length of pseudobulbs relation occurred, as well as in the number of roots of the plants grown under white light + red light. On the other hand, plants grown under white light did not respond to immersion time. Immersion in distilled water, regardless of light conditions, is not recommended for $D$. phalaenopsis.
\end{abstract}

Keywords: Orchidaceae, floriculture, water immersion, light conditions.

\section{(Recebido para publicação em 18 de agosto de 2014; aceito em 21 de julho de 2015) (Received on August 18, 2014; accepted on July 21, 2015)}

$\mathrm{O}$ gênero Dendrobium constitui-se de plantas que florescem em grande escala, e juntamente com os gêneros Oncidium, Cymbidium, Phalaenopsis e Cattleya é promissor para o comércio tanto de flores de corte quanto para plantas envasadas (Kiyuna, 2004).

As orquídeas são usualmente multiplicadas por técnicas de cultivo in vitro. Apesar do sucesso dessas técnicas, um número expressivo de indivíduos micropropagados não sobrevive às condições ex vitro (Hazarika, 2003). Isso ocorre parcialmente devido às condições ambientais durante a micropropagação quais sejam elevada umidade relativa do ar (superior a 90\%), baixa irradiação, limitados potenciais osmóticos e baixa troca de $\mathrm{CO}_{2}$ Estas condições contribuem para uma alta taxa de multiplicação, mas também induzem o aparecimento de anormalidades anatômicas, morfológicas e fisiológicas (Chandra et al., 2010). Dendrobium phalaenopsis apresenta boa porcentagem de germinação e desenvolvimento em meio assimbiótico, entretanto a sua aclimatização ex vitro ainda requer estudos, uma vez que o grande número de indivíduos produzidos por frasco de 
cultivo, muitas vezes inviabiliza o seu transplante imediato para os substratos de aclimatização, devido à escassez de mão de obra especializada e do tempo necessário a essa prática. $\mathrm{O}$ processo de transplante da condição in vitro para a ex vitro pode ocasionar a desidratação das plantas produzidas com consequente morte ou retardamento no processo de crescimento e desenvolvimento (Lavanya et al., 2009).

Alguns procedimentos que antecedem a aclimatização em viveiros permitem elevar a taxa de sobrevivência das plantas, evitando que elas se desidratem e murchem durante e após o transplantio. A taxa de sobrevivência de plantas de Vitis labrusca micropropagadas foi elevada removendo-se as tampas dos frascos de cultivo, ainda em sala de crescimento, por 2 a 5 dias antes do transplante (Schuck et al., 2012). Para aclimatização de Bowdichia virgilioides, Moura et al. (2012) cobriram as plantas recém retiradas dos recipientes de cultivo in vitro com polipropileno transparente provido de orifícios para ventilação, propiciando um ambiente com umidade relativa mais alta que o do viveiro.

A condição de luminosidade é outro fator que influencia a aclimatização da maioria das orquídeas epífitas, que por serem componente de florestas tropicais úmidas (Ricklefs, 2010), são adaptadas à baixa intensidade luminosas (Taveira, 2011). A percepção do sinal luminoso pelas plantas requer que a luz seja absorvida e se torne metabolicamente ativa, o que é efetuado pelos fotorreceptores ou pigmentos especializados, responsáveis pelas respostas fotomorfogênicas das plantas. Entre os pigmentos que podem promover essas respostas nas plantas, os mais importantes são os fitocromos que absorvem principalmente o vermelho e o vermelho-extremo (picos máximos de absorção entre 650-680 e 710-740 nm, respectivamente) e os criptocromos que absorvem o azul e o ultravioleta (picos máximos de absorção entre 425-490 e 320-400 $\mathrm{nm}$, respectivamente) (Majerowicz \& Peres, 2008).

$\mathrm{Na}$ fotossíntese são utilizados os comprimentos de onda relativos ao azul e ao vermelho. Os comprimentos vermelho e vermelho extremo ativam os processos de morfogênese, enquanto que o azul, o violeta e o ultravioleta ativam o fototropismo (Kämpf, 2005; Majerowicz \& Peres, 2008). Devido à importância da luz vermelha na fotomorfogênese, diversos autores têm estudado esse comprimento de onda como forma de propiciar maior crescimento e desenvolvimento de plantas cultivadas in vitro (Tanaka et al., 1998; Cybularz-Urban et al., 2007; Araújo et al., 2009; Galdiano Junior et al., 2012).

Em vista do exposto objetivou-se com esse trabalho estudar o efeito conjunto do período de imersão de plantas em água destilada e de duas condições de luminosidade em tratamentos de aclimatização intermediária para Dendrobium phalaenopsis. Espera-se que a imersão das plantas em água possa prolongar o período de transplante para os substratos de aclimatização, minimizando a desidratação e que a alteração das condições de luminosidade possa contribuir para ativação de respostas morfofisiológicas que propiciem maior sobrevivência e desenvolvimento ex vitro.

\section{MATERIAL E MÉTODOS}

O experimento foi realizado no Laboratório de cultivo in vitro e na área de Jardinocultura da Faculdade de Ciências Agrárias da Universidade Federal da Grande Dourados, durante o período de agosto de 2011 a julho de 2012.

Foram utilizadas como material de estudo, plantas de Dendrobium phalaenopsis, com 180 dias, oriundas de semeadura in vitro, cultivadas em meio MS e mantidas em sala de crescimento com temperatura média de $25 \pm 2^{\circ} \mathrm{C}$ e fotoperíodo de 12 horas, com intensidade luminosa de 18,9 $\mu \mathrm{mol} /$ $\mathrm{m}^{2} / \mathrm{s}$ obtida por meio de duas lâmpadas brancas fluorescentes de $40 \mathrm{~W}$ cada.

As plantas foram retiradas dos frascos de cultivo, lavadas em água corrente, até total remoção do meio de cultura, e padronizadas quanto ao comprimento da parte aérea $(1,2 \mathrm{~cm})$. A seguir, foram avaliadas quanto à massa fresca $(0,5 \pm 0,1$ $\mathrm{g})$, número de folhas $(6,2 \pm 2,0)$, comprimento do maior pseudobulbo $(0,8 \pm 0,2$ $\mathrm{cm}$ ), diâmetro do maior pseudobulbo
$(0,3 \pm 0,1 \mathrm{~cm})$, número de pseudobulbos $(2,3 \pm 1,0)$, número de raízes $(2,9 \pm 0,1)$ e comprimento da maior raiz $(2,9 \pm 1,0$ $\mathrm{cm})$.

Na sequência, dividiu-se aleatoriamente em conjuntos de 40 plantas cada. Cada conjunto de plantas foi submetido a um período de imersão $(12 ; 24 ; 36 ; 48$; $60 ; 72$ ou 84 horas), com a utilização de Beckers com capacidade para $500 \mathrm{~mL}$, contendo cada um $250 \mathrm{~mL}$ de água destilada previamente esterilizada, por 20 minutos, em autoclave $\left(120^{\circ} \mathrm{C}\right.$ e $1 \mathrm{~atm}$ de pressão) e posteriormente resfriada à temperatura ambiente $\left(25 \pm 2^{\circ} \mathrm{C}\right)$. Os Beckers contendo as plantas foram acondicionados na sala de crescimento anteriormente descrita. A água de cada conjunto foi trocada a cada 12 horas. Após cada período de imersão, as plantas foram transplantadas para recipientes de polipropileno descartáveis com capacidade para $50 \mathrm{~cm}^{3}$, apresentando diâmetro médio de 5,0 cm e altura de 4,0 $\mathrm{cm}$, providos de furos para drenagem, contendo, como substrato, a mistura de esfagno rosa (Agrolink, Holambra-SP) e fibra de coco (Golden-Mix Chips, Amafibra $\left.^{\circledR}\right)(1: 1 \mathrm{v} / \mathrm{v})$. Um conjunto de plantas, considerado como controle, não foi submetido à imersão, sendo as plantas acondicionadas diretamente no substrato.

Cada recipiente, contendo uma planta, foi transferido para sala de crescimento com fotoperíodo e temperatura controlados $\left(12 \mathrm{~h} ; 25 \pm 2^{\circ} \mathrm{C}\right)$, por 30 dias, para a aclimatização intermediária, recebendo duas pulverizações diárias com água destilada utilizando-se pulverizadores manuais.

Durante esse período as plantas foram submetidas a duas condições de luminosidade. Metade dos indivíduos (20 plantas de cada período de imersão e do controle) permaneceu sob luz fluorescente branca (B) $(18,9 \mu \mathrm{mol} /$ $\mathrm{m}^{2} / \mathrm{s}$ ) fornecida por duas lâmpadas fluorescentes branca de $40 \mathrm{~W}$ cada, e a outra metade foi transferida para a condição de luz fluorescente branca + luz fluorescente vermelha (BV) $(14,85$ $\mu \mathrm{mol} / \mathrm{m}^{2} / \mathrm{s}$ ) produzida por uma lâmpada fluorescente branca de $40 \mathrm{~W}$ e uma lâmpada fluorescente vermelha de 30 W (Gro-lux $\left.{ }^{\circledR}\right)$.

Após o período de aclimatização in- 
termediária as plantas foram transferidas para viveiro coberto pela sobreposição de duas telas de sombreamento de $50 \%$ (162,0 $\left.\mu \mathrm{mol} / \mathrm{m}^{2} / \mathrm{s}\right)$ sob condições médias de temperatura e umidade relativa de $22,6 \pm 5^{\circ} \mathrm{C}$ e $73,9 \pm 10 \%$, respectivamente, para a aclimatização definitiva por 10 meses. Durante este período, semanalmente, as plantas foram irrigadas com uma lâmina de água de $3 \mathrm{~mm}$, dividida em três aplicações de $1 \mathrm{~mm}$ cada, sendo descontados os volumes das precipitações pluviométricas. $\mathrm{O}$ sistema de irrigação utilizado durante o período experimental foi constituído de difusores, posicionados um metro acima das plantas, acionados automaticamente por temporizador digital e válvula solenóide.

As plantas foram adubadas semanalmente, via foliar, com 2,0 mL/L de NPK 10-10-10, acrescido dos seguintes micronutrientes: 0,025\% de magnésio, $0,02 \%$ de boro, $0,05 \%$ de cobre, $0,10 \%$ de ferro, $0,05 \%$ de manganês, $0,0005 \%$ de molibdênio e $0,05 \%$ de zinco, com teor máximo de cloro de $0,025 \%$. A cada 30 dias as plantas foram desinfestadas, preventivamente, com O-S-dimetil-N-acetil-fosforamidotioato (4 mg/L) e Mancozebe (4 mg/L). Tanto para a adubação foliar, quanto para a desinfestação, foi utilizado pulverizador costal com capacidade para $5 \mathrm{~L}$.

Após o período de aclimatização definitiva, as plantas foram removidas do substrato e lavadas em água corrente. A seguir foram avaliadas quanto a porcentagem de sobrevivência, a massa fresca $(3,6 \pm 0,2 \mathrm{~g})$, número de folhas $(7,6 \pm 3,0)$, comprimento do maior pseudobulbo $(1,9 \pm 1,0 \mathrm{~cm})$, diâmetro do maior pseudobulbo $(0,8 \pm 0,2 \mathrm{~cm})$, número de pseudobulbos $(3,5 \pm 1,0)$, comprimento da maior raiz $(9,2 \pm 4,0 \mathrm{~cm})$ e número final de raízes $(11,6 \pm 5,0)$.

Dado o interesse em investigar a hipótese de aumento nos valores de massa fresca, número de folhas, número de pseudobulbos, comprimento do maior pseudobulbo, diâmetro do maior pseudobulbo, número de raízes e comprimento da maior raiz observados no final do período experimental (VF), em relação àqueles registrados no plantio (VP), foram calculados suas relações (R), por meio da expressão $\mathrm{R}=\mathrm{VF} / \mathrm{VP}$ sendo estes os valores considerados nas análises estatísticas, juntamente com a porcentagem de sobrevivência.

O delineamento experimental utilizado foi inteiramente casualizado e os tratamentos foram arranjados em esquema de parcela subdivididas, sendo alocados na parcela os oito períodos de imersão e, na subparcela, as duas condições de luminosidade com 20 repetições de uma planta. Para análise estatística utilizou-se o aplicativo computacional SISVAR 5.3 (Ferreira, 2010). Os resultados expressos em porcentagem assim como aqueles oriundos de variáveis discretas foram transformados por meio da função $\sqrt{x+1}$ e a seguir foram avaliados mediante análise de variância e, posteriormente, as médias foram comparadas por meio do teste de Student até o nível de $5 \%$ de probabilidade. Os fatores quantitativos foram avaliados por meio de regressão.

\section{RESULTADOS E DISCUSSÃO}

Ao final de 10 meses de aclimatização, todas as relações estudadas, apresentaram resultados superiores a 1,0 , indicando que as plantas, independentemente dos tratamentos estudados, confirmam a hipótese de que houve aumento dos parâmetros estudados no final do período experimental. Os maiores aumentos (em ordem decrescente) foram registrados na relação da massa fresca $(\mathrm{RMF}=7,1)$, número de raízes $(\mathrm{RNR}=3,9)$, comprimento da maior raiz $(\mathrm{RCMR}=3,4)$, comprimento do maior pseudobulbo $(\mathrm{RCMB}=2,5)$, diâmetro do maior pseudobulbo $(\mathrm{RDMB}=2,5)$, número de pseudobulbos $(\mathrm{RNB}=1,8) \mathrm{e}$ número de folhas $(\mathrm{RNF}=1,4)$.

Interação significativa entre o tempo de imersão e a condição de luminosidade $(\mathrm{p}<0,05)$ foi observada sobre as relações da massa fresca, comprimento de pseudobulbos, número de raízes e comprimento da maior raiz. Efeitos isolados do tempo de imersão $(p<0,01)$ foram registrados para todas as variáveis, enquanto que a condição de luminosidade atuou isoladamente $(\mathrm{p}<0,05)$ sobre as relações da massa fresca, comprimento do maior pseudobulbo e número de raízes.

Quando as plantas de D. phalaenopsis foram submetidas à aclimatização intermediária, os efeitos combinados do tempo de imersão em água destilada só foram observados com a utilização da luz branca + vermelha (BV). Plantas aclimatizadas sob luz branca (B) não foram influenciadas $(p>0,05)$ pelo tempo de imersão e os valores médios apresentados pelas relações da massa fresca, comprimento do maior pseudobulbo, comprimento da maior raiz e número de raízes foram 5,$3 ; 1,2 ; 2,4$ e 3,5 respectivamente (Figura 1A, B, C e D).

Quando as plantas foram submetidas à aclimatização intermediária com luz BV, os melhores resultados foram observados na ausência de imersão e apresentaram efeitos lineares decrescentes, à medida que o tempo de imersão aumentou, para RMF (Figura 1A), RCMB (Figura 1B), RCMR (Figura 1C) e RNR (Figura 1D).

Os efeitos favoráveis da luz BV em relação à luz $\mathrm{B}$ nas plantas puderam ser registrados até o tempo de imersão de 48 horas para RMF, RCMB e RNR (Figura 1A, B e D). De maneira análoga, a utilização de luz vermelha promoveu o alongamento de plantas de Cattleya loddigesii cultivadas in vitro (Araújo et al., 2009), elevou as médias de relação de massa fresca de Dendrobium phalaenopsis (Sorgato et al., 2015), aumentou o comprimento de broto para híbrido de Cattleya (Cybularz-Urban et al., 2007). A utilização de LED (light-emitting diodes) azul e vermelha propiciaram aumento no crescimento de plantas de Cymbidium (Tanaka et al., 1998).

Já para RCMR os resultados observados para luz BV foram superiores aos da luz B em todos os tempos de imersão (Figura 1C). Esses resultados se contrapõem ao relato de Galdiano Junior et al., (2012) no qual a utilização de luz vermelha reduziu o comprimento da maior raiz de Cattleya loddigesii durante a aclimatização.

O aumento do tempo de imersão das plantas associado à exposição subsequente à luz BV pode ter ativado o mecanismo de ação do fitocromo. Esse mecanismo regula as mudanças nos fluxos iônicos em nível de membrana lipoproteica, provocando alterações na permeabilidade da membrana (Majerowicz \& Peres, 2008) interferin- 


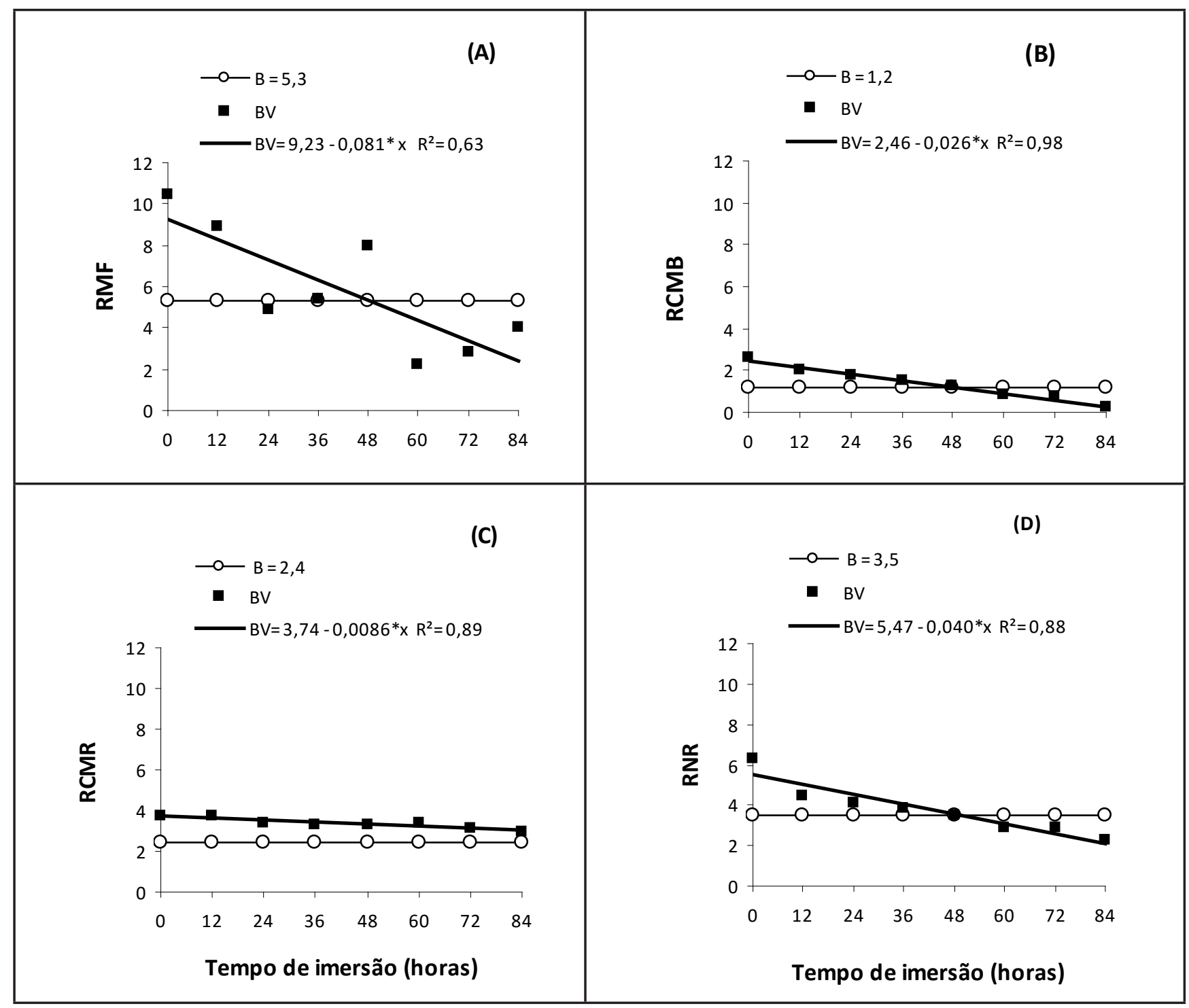

Figura 1. Efeito conjunto do tempo de imersão e das condições de luminosidade (B= luz branca; $B V=50 \%$ de luz branca $+50 \%$ de luz

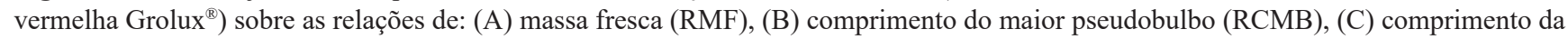
maior raiz $(\mathrm{RCMR})$ e $(\mathrm{D})$ número de raízes $(\mathrm{RNR})$ de Dendrobium phalaenopsis \{combined effect of immersion time and light conditions (B= white light; $\mathrm{BV}=50 \%$ of white light $+50 \%$ red light Grolux $^{\circledR}$ ) on the relations of: (A) fresh mass (RMF), (B) length of the largest pseudobulb (RCMB), (C) length of the longest root (RCMR) and (D) number of roots (RNR) of Dendrobium phalaenopsis \}. Dourados, UFGD, 2012.

do no crescimento das plantas cultivadas sob essa condição de luminosidade.

A porcentagem de sobrevivência (Figura 2A), e as relações do diâmetro do maior pseudobulbo (Figura 2B), número de pseudobulbos (Figura 2C) e número de folhas (Figura 2D) de $D$. phalaenopsis foram influenciadas isoladamente, apenas pelo tempo de imersão $(p<0,01)$. Para cada 12 horas de imersão, houve redução de 5,8\% na sobrevivência das plantas, e de 0,11 na relação do diâmetro do maior pseudobulbo, 0,16 na relação no número de pseudobulbos e 0,12 na relação do número de folhas
(Figura 2A, B, C e D).

Tempo de imersão superior a 76 horas propiciou relação inferior a 1,0 no número de folhas (Figura 2B). Este resultado pode ser decorrente do estresse ocasionado pela aclimatização, uma vez que as características fisiológicas e anatômicas de plantas cultivadas in vitro requerem aclimatização gradual ao ambiente ex vitro (Hazarika, 2003). Em decorrência disso, em algumas espécies, as folhas formadas in vitro não se apresentam aptas às condições ex vitro, sendo substituídas por outras (Diettrich et al., 1992).
Embora a imersão em água destilada por até 30 horas, independentemente da condição de luminosidade estudada, tenha possibilitado porcentagem de sobrevivência superior a 75\% (Figura 2A) na aclimatização definitiva, valor este considerado satisfatório para cultivos comerciais (Sorgato et al., 2015), os resultados deste trabalho indicam que o transplante imediato (sem a prática da imersão em água) de $D$. phalaenopsis para substrato e sua posterior aclimatização intermediária, com luz BV, apresentam resultados relativos à porcentagem de sobrevivência e às demais variáveis 


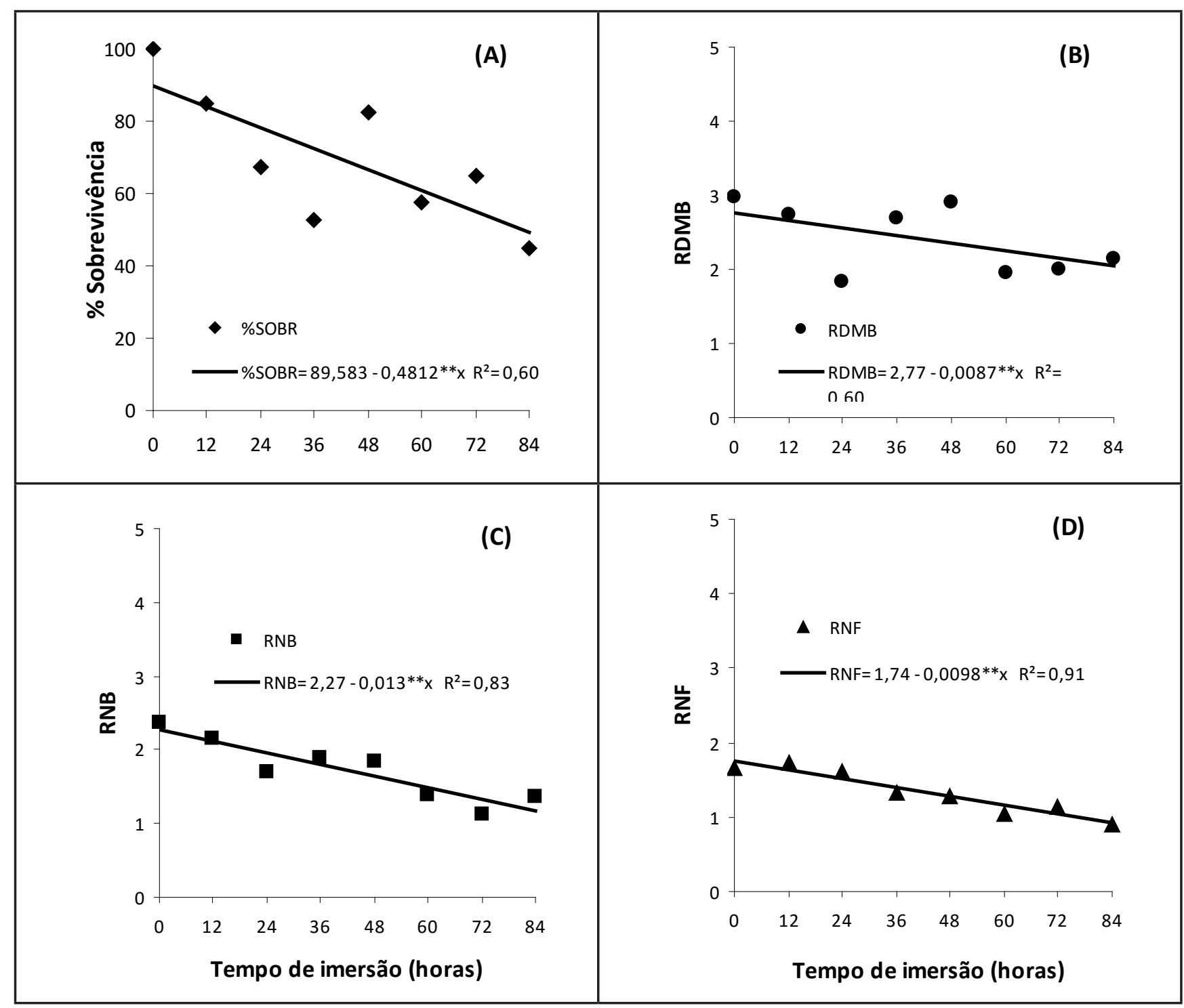

Figura 2. Efeito isolado do tempo de imersão em água destilada sobre (A) a porcentagem de sobrevivência (\%SOBR) e sobre as relações de (B) diâmetro do maior pseudobulbo (RDMB), (C) número de pseudobulbos (RNB) e (D) número de folhas (RNF) de Dendrobium phalaenopsis \{isolated effect of immersion time in distilled water on (A) the percentage of survival (\%SOBR) and the relations of (B) diameter of the largest pseudobulb (RDMB), (C) number of pseudobulbs (RNB) and (D) number of leaves (RNF) of Dendrobium phalaenopsis\}. Dourados, UFGD, 2012.

estudadas superiores, sendo portanto, mais recomendado para a espécie.

Com base nos resultados, os autores concluem que as plantas de Dendrobium phalaenopsis não devem ser imersas em água na aclimatização intermediária e devem ser mantidas por 30 dias em sala de crescimento sob luz fluorescente branca + luz fluorescente vermelha na proporção de 50-50.

\section{REFERÊNCIAS}

AM. 2009. Crescimento in vitro de Cattleya loddigesii Lindl. em diferentes espectros luminosos associados com ácido giberélico. Ceres 56: 542-546.

CHANDRA S; BANDOPADHYAY R; KUMAR V; CHANDRA R. 2010. Acclimatization of tissue cultured plantlets: from laboratory to land. Biotechnology Letters 32: 1199-1205.

CYBULARZ-URBAN T; HANUS-FAJERSKA E; SWIDERSKI A. 2007. Effect of light wavelength on in vitro organogenesis of a Cattleya hybrid. Acta Biologica Cracoviensia 49: 211-220.

DIETTRICH B; MERTINAT H; LUCKNER M. 1992. Reduction of waterloss during ex vitro acclimatization of micropropagated Digitalis lanata clone plants. Biochemie und Physiologie der Pflanzen 188: 23-31.

FERREIRA DF. 2010. Programa de análises estatísticas (Statistical Analysis Software) e planejamento de experimentos - SISVAR 5.3. Lavras: UFLA.

GALDIANO JUNIOR RF; MANTOVANI C; PIVETTA KFL; LEMOS EGM. 2012. Crescimento in vitro e aclimatização de Cattleya loddigesii Lindley (Orchidaceae) com carvão ativado sob dois espectros luminosos. Ciência Rural 42: 801-807.

HAZARIKA BN. 2003. Acclimatization of tissuecultured plants. Current Scienc 85: 1704-1712.

KÄMPF AN. 2005. Produção comercial de plantas ornamentais. 2.ed. Guaíba: Agropecuária. 254p.

KIYUNA I; FRANCISCO VLFS; COELHO PJ; CASER DV; ASSUMPÇÃO RD; ÂNGELO JA. 2004. Floricultura brasileira no início do século XXI: o perfil do produtor. Informações Econômicas 34: 14-31. 
LAVANYA M; VENKATESHWARLU B; DEVI BP. 2009. Acclimatization of neem microshoots adaptable to semi-sterile conditions. Indian Journal of Biotechnology 8: 218-222.

MAJEROWICZ N; PERES LEP. Fotomorfogênese em plantas. In: KERBAUY GB. Fisiologia Vegetal. 2.ed. Rio de Janeiro: Guanabara Koogan S.A., 2008. 431p.

MOURA LC; TITON M; FERNANDES JSC; SANTANA RC; OLIVEIRA MLR. 2012. Micropropagação de sucupira-preta por meio de gemas axilares. Pesquisa Agropecuária Brasileira 47: 1691-1698.
RICKLEFS RE. A economia da natureza. 6. ed. Rio de Janeiro: Guanabara Koogan S.A. 2010. 570p

SCHUCK MR; LIPSKI B; SILVA ALL; CARVALHO DC; BIASI LA. 2012. Aclimatização de plantas micropropagadas de videira cv. Bordô (Vitis labrusca L.) em diferentes substratos. Journal of Biotechnology and Biodiversity 3: 206-212.

SORGATO JC; ROSA YBCJ; SOARES JS; LEMES CSR; SOUSA GGD. 2015. Light in intermediate acclimatization of in vitro germinated seedlings of Dendrobium phalaenopsis Deang Suree. Ciência Rural 45: 231-237.

TANAKA M; TAKAMURA T; WATANABE $\mathrm{H}$; ENDO M; YANAGI T; OKAMOTO K. 1998. In vitro growth of Cymbidium plantlets cultured under super bright red and blue light-emitting diodes (LEDs). Journal of Horticultural Science and Biotechnology 73: 39-44.

TAVEIRA JAM. Novas tecnologias na aclimatização, formação e manejo de mudas. In: GERALD LTS (ed). Biofábrica de plantas: produção industrial de plantas in vitro. São Paulo: Antiqua, 2011. 383p. 